BNL-81715-2008-IR

\title{
Vacuum Systems Consensus Guideline for Department of Energy Accelerator Laboratories
}

\author{
Co-authored by: \\ R. Casey, E. Haas, H-C Hseuh, S. Kane, E. Lessard, S. Sharma, BNL \\ J. Collins, W. F. Toter, ANL \\ D. R. Olis, D. R. Pushka, FNL \\ P. Ladd, ORNL \\ R. K. Jobe, SLAC
}

September 9, 2008

\author{
Brookhaven National Laboratory \\ P.O. Box 5000 \\ Upton, NY 11973-5000 \\ www.bnl.gov
}

\footnotetext{
Notice: This manuscript has been authored by employees of Brookhaven Science Associates, LLC under Contract No. DE-AC02-98CH10886 with the U.S. Department of Energy. The publisher by accepting the manuscript for publication acknowledges that the United States Government retains a non-exclusive, paid-up, irrevocable, world-wide license to publish or reproduce the published form of this manuscript, or allow others to do so, for United States Government purposes.
} 


\section{DISCLAIMER}

This report was prepared as an account of work sponsored by an agency of the United States Government. Neither the United States Government nor any agency thereof, nor any of their employees, nor any of their contractors, subcontractors, or their employees, makes any warranty, express or implied, or assumes any legal liability or responsibility for the accuracy, completeness, or any third party's use or the results of such use of any information, apparatus, product, or process disclosed, or represents that its use would not infringe privately owned rights. Reference herein to any specific commercial product, process, or service by trade name, trademark, manufacturer, or otherwise, does not necessarily constitute or imply its endorsement, recommendation, or favoring by the United States Government or any agency thereof or its contractors or subcontractors. The views and opinions of authors expressed herein do not necessarily state or reflect those of the United States Government or any agency thereof. 


\section{Foreword}

This document has its origins in discussions that took place at the Accelerator Safety Workshop sponsored by the Department of Energy's (DOE) Office of Science on August 7-9, 2007.

Concern was expressed at that meeting with regard to the interpretation of Title 10, Code of Federal Regulations, Part 851, "Worker Safety and Health Program" (10 CFR 851) requirements as they apply to the design standards for vacuum vessels and associated components.

A working group was formed in January 2008 to study these issues and to develop guidance for the design, construction, testing, operation, inspection, and maintenance of vacuum vessels and associated components. The Working group members are:

Argonne National Laboratory

Jeffrey T Collins

William $\mathrm{F}$ Toter

Brookhaven National Laboratory

Robert Casey (Chair)

Edwin Haas

Hsiao-Chaun (Dick) Hseuh

Steven Kane

Edward Lessard

Sushil Sharma

Fermi National Accelerator Laboratory

Daniel R Olis

David R Pushka

Oak Ridge National Laboratory

Peter Ladd

Stanford Accelerator Laboratory

$R$. Keith Jobe

A draft Guideline was prepared by the Working Group and presented at the Accelerator Safety Workshop sponsored by the Department of Energy's (DOE) Office of Science on August 12-14, 2008. Two break-out sessions were conducted and a consensus was reached in support of the present document. In addition to members of the initial working group, additional participation included:

Michael J. Baumgartner (LANL)

Edward Daly (TJNL)

Michael Gaffney (BNL)

Thomas Mullen (ANL)

Will Oren (TJNL)

1 "Code of Federal Regulations: Main Page", http://www.gpoaccess.gov/cfr/ 


\section{Vacuum Systems Consensus Guideline for DOE Accelerator Laboratories}

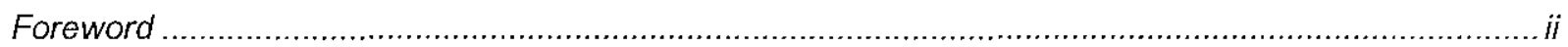

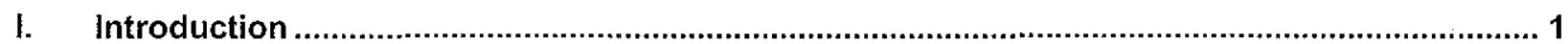

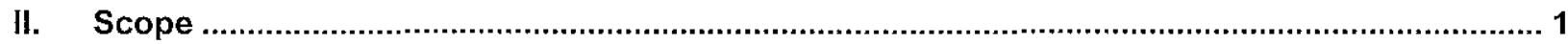

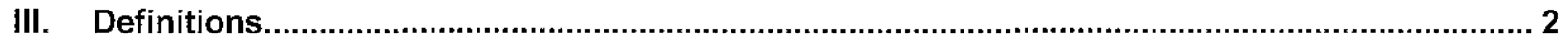

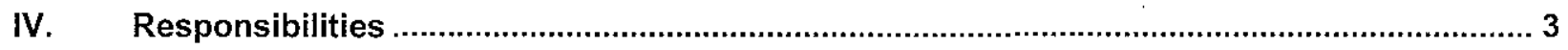

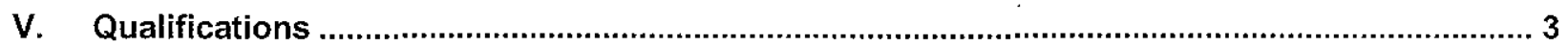

Responsible Vacuum System Design Engineer ..................................................................... 3

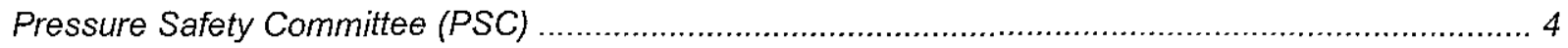

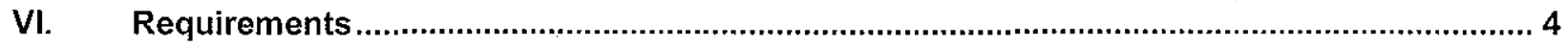

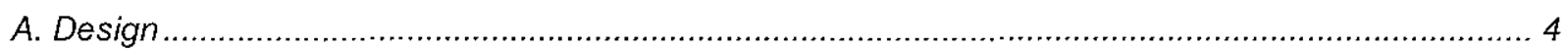

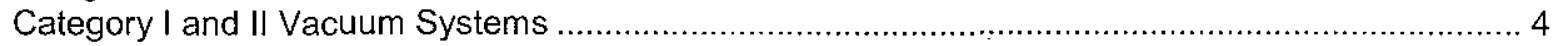

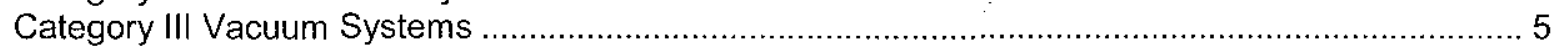

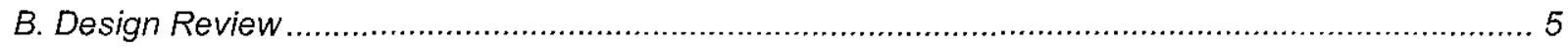

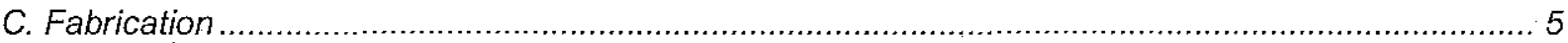

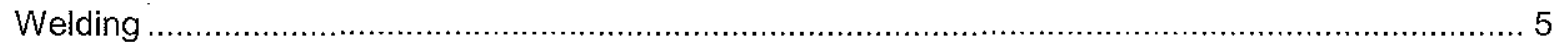

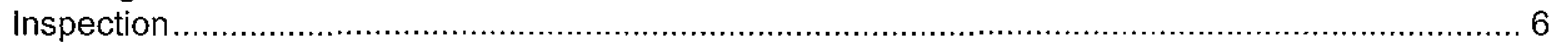

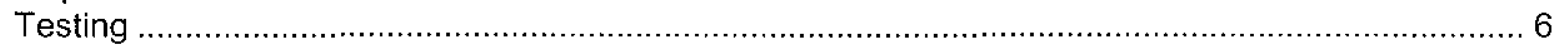

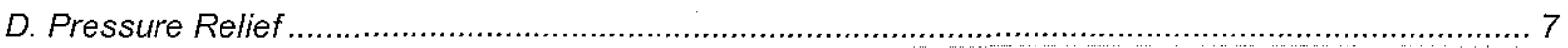

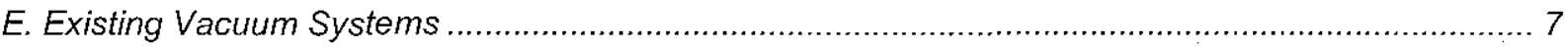

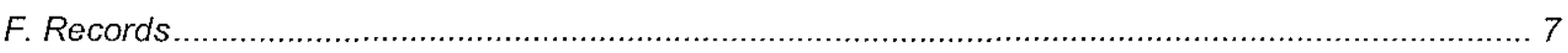

Appendix A: Engineering Evaluation Requirements .............................................................. 9

Appendix B: Independent Review Requirements for Category III Vacuum Vessels........................ 10

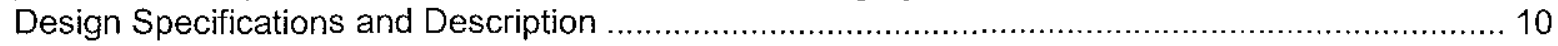

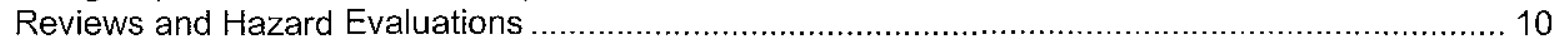

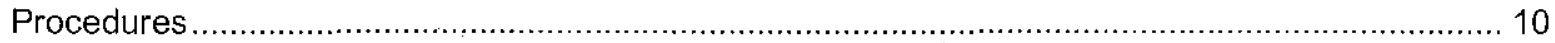




\section{Introduction}

Vacuum vessels, including evacuated chambers and insulated jacketed dewars, can pose a potential hazard to equipment and personnel from collapse, rupture due to back-fill pressurization, or implosion due to vacuum window failure. It is therefore important to design and operate vacuum systems in accordance with applicable and sound engineering principles.

10 CFR 851 defines requirements for pressure systems that also apply to vacuum vessels subject to back-fill pressurization. Such vacuum vessels are potentially subject to the requirements of the American Society of Mechanical Engineers (ASME) Pressure Vessel Code Section VIII (hereafter referred to as the "Code"). However, the scope of the Code excludes vessels with internal or external operating pressure that do not exceed 15 pounds per square inch gauge (psig). Therefore, the requirements of the Code do not apply to vacuum systems provided that adequate pressure relief assures that the maximum internal pressure within the vacuum vessel is limited to less than 15 psig from all credible pressure sources, including failure scenarios.

Vacuum vessels that cannot be protected from pressurization exceeding $15 \mathrm{psig}$ are subject to the requirements of the Code. 10 CFR 851, Appendix A, Part 4, Pressure Safety, Section C addresses vacuum system requirements for such cases as follows:

"(c) When national consensus codes are not applicable (because of pressure range, vessel geometry, use of special materials, etc.), contractors must implement measures to provide equivalent protection and ensure a level of safety greater than or equal to the level of protection afforded by the ASME or applicable state or local code. Measures must include the following:

(1) Design drawings, sketches, and calculations must be reviewed and approved by a qualified independent design professional (i.e., professional engineer). Documented organizational peer review is acceptable.

(2) Qualified personnel must be used to perform examinations and inspections of materials, in-process fabrications, non-destructive tests, and acceptance test.

(3) Documentation, traceability, and accountability must be maintained for each unique pressure vessel or system, including descriptions of design, pressure conditions, testing, inspection, operation, repair, and maintenance."

The purpose of this guideline is to establish a set of expectations and recommendations which will satisfy the requirements for vacuum vessels in general and particularly when an equivalent level of safety as required by 10 CFR 851 must be provided. It should be noted that these guidelines are not binding on DOE Accelerator Laboratories and that other approaches may be equally acceptable in addressing the Part 851 requirements.

\section{Scope}

This document establishes guidelines for the design, construction, and operation of vacuum vessels designed and built after February $9,2007 .^{2}$ This guideline also includes

\footnotetext{
${ }^{2} 10$ CFR 851 came into effect on February 9, 2007. The date that an approved worker safety and health program had to be in place was May 25, 2007.
} 
recommendations for, testing, inspection, repair, and maintenance of vacuum piping, vessels, and systems.

For connected sections, such as particle accelerator rings, the boundary of the vacuum vessel extends to the bolted flange or circumferential weld that connects the sections.

This guideline applies to all vacuum vessels except those with a total energy less than 20,000 joules ${ }^{3}(\mathrm{~J})$. This excludes:

1. Any vacuum vessel with a volumetric capacity of less than 7 cubic feet $\left(\mathrm{ft}^{3}\right)$

2. Any vessel under external pressure whose product $P \times V$ is less than $73\left(p s i-\mathrm{ft}^{3}\right)$, where $P$ is the external differential maximum allowable working pressure (MAWP) in pounds per square inch (psi) and $V$ is the volumetric capacity in $\mathrm{ft}^{3}$

In addition, this guideline does not apply to any vacuum vessel with a cross-sectional area less than 28 square inches $\left(i^{2}\right)$. (This is equivalent to the cross-section of a 6 -inch diameter pipe). There is no limitation on the length of the vacuum vessel.

Vacuum vessels with thin or brittle vacuum windows require special consideration not addressed in this guideline; however, windows are likely to be the weakest component of the vacuum vessel in terms of an implosion hazard.

Any vacuum vessel that cannot be protected against credible failures that result in internal overpressurization greater than 15 psig is subject to this guideline.

\section{Definitions}

Note: The position titles used in the following paragraphs are generic.

Authority having jurisdiction (AHJ) - The person or committee identified by the laboratory director as having the experience and knowledge of pressure/vacuum codes and standards to make sound judgments with respect to laboratory pressure safety policy

Engineering evaluation - A document prepared by the responsible engineer that demonstrates that a given system satisfies the requirements of this guideline. The evaluation provides a basis for independent review of design and installation, as well as a record of the system design parameters for future system users. The evaluation is expected to address the topics listed in Appendix A of this guideline.

Independent design professional - A person responsible for independent review of the design of a vacuum system subject to the requirements of this guideline. This person is normally appointed by the division manager or other responsible manager and must meet the qualification requirements defined in Section $\mathrm{V}$.

\footnotetext{
${ }^{3}$ For more discussion of this threshold, see ASME PCC-2-2006 "Standard For The Repair Of Pressure Equipment And Piping", Article 5.1, Appendix II, "Stored Energy Calculations for Pneumatic Pressure Test", and Article 5.1, Appendix III, "Safe Distance Calculations for Pneumatic Pressure Test". Additional information is also available in Los Alamos National Laboratory. Laboratory Implementation Requirement (LIR) 402-1200-01.0, Pressure, Vacuum, and Cryogenic Systems, October 1, 1999. Los Alamos National Laboratory.
} 
Pressure Safety Committee (PSC) - A committee appointed by the laboratory director or other responsible manager to provide guidance and oversight to the Laboratory with regard to pressure safety. Depending on local practices at each institution, the PSC may review new or modified designs of vacuum/pressure systems subject to this guideline and/or serve as the authority having jurisdiction for matters of pressure safety for the facility.

Responsible vacuum system design engineer - The person responsible for the engineering design of a vacuum system. This person must meet the qualification requirements defined in Section $V$, and is normally appointed by a responsible manager of the organization accountable for operation of the vacuum system.

Vacuum system - A system consisting of a vessel and its associated piping and components evacuated below atmospheric pressure. Guidelines for vacuum vessels are determined according to the category that describes the vessel:

Category I Vacuum vessels in which the differential operating pressure across the vacuum boundary can never exceed 15 psi

Category II Vacuum vessels that are protected from credible failures that could create pressurization exceeding $15 \mathrm{psi}$ through the use of engineering controls such as pressure relief devices

Category III Vacuum vessels that are not or cannot be protected from credible failures that could create pressurization exceeding 15 psi

\section{Responsibilities}

A responsible manager for the organization designing or operating a vacuum vessel assures implementation of this guideline. He/she assigns a qualified responsible vacuum system design engineer to design the vacuum system in accordance with applicable codes and to prepare the required engineering evaluation. A responsible manager also assures operation and maintenance of the vacuum system consistent with this guideline throughout the operating period of the system.

The authority having jurisdiction at an institution is responsible for the official interpretation of codes, standards, and practices relating to this guideline and the ASME Codes. All issues regarding interpretation and application of this guideline should be referred to this authority for resolution.

The Pressure Safety Committee advises the operating organizations and laboratory director regarding pressure safety issues associated with all facility operations. In some organizations the Pressure Safety Committee is responsible for independent review of vacuum/pressure system design and may serve as the authority having jurisdiction for matters of vacuum/pressure safety.

\section{Qualifications}

\section{Responsible Vacuum System Design Engineer}

The responsible vacuum system engineer should possess extensive relevant knowledge, training, and experience. In addition, the engineer should have successfully demonstrated 
his/her ability to solve or resolve problems relating to the system under review in terms of its nature, complexity, and criticality. Approval from the facility authority having jurisdiction is required if the individual does not meet at least one of the following criteria:

(1) Completion of an engineering Bachelor of Science or similar degree, requiring 4 or more years of full-time study, plus a minimum of 5 years of experience in the design of related vacuum/pressure systems

(2) Professional engineering registration recognized by the local jurisdiction, plus experience in the design of related vacuum/pressure systems

(3) Completion of an Associate of Engineering degree, requiring at least 2 years of full-time study, plus a minimum of 10 years of experience in the design of related vacuum/pressure systems

(4) Fifteen years of experience in the design of related vacuum/pressure systems, which is satisfied by experience that includes vacuum/pressure system design calculations and equipment and material selection.

These qualification requirements also apply to any individual serving in the role of an independent design professional responsible for conducting a review.

\section{Pressure Safety Committee (PSC)}

Members of the PSC are appointed by the laboratory director or delegate and should be experienced and knowledgeable in the design and operation of vacuum/pressure systems. Technical competence for each member should be evidenced by 15 years of employment as a safety professional, physicist, or engineer. A Bachelor of Science degree or higher is recommended. Individual members are not expected to be expert in all topic areas, but the committee as a whole should possess the capability to evaluate all of the topics in Appendix B of this guideline. At least one member of the PSC should possess the qualifications identified for the responsible vacuum system design engineer.

\section{Requirements}

\section{A. Design}

The application of sound engineering principles and practices are expected in the design and operation of all vacuum systems. All vacuum vessels shall be designed to ensure that allowable stresses are not exceeded and to ensure that the vessel is stable (resistant to buckling). The design should be documented in the engineering evaluation as described in Appendix A. All issues regarding interpretation of these requirements should be referred to the authority having jurisdiction by the responsible manager.

\section{Category I and II Vacuum Systems}

Vacuum vessels in these categories are not required to be stamped with ASME Code Symbol Stamp. For vacuum systems in Categories I and II, the allowable compressive stresses should 
be calculated using ASME Code Case 2286, July 17, 1998. ${ }^{4}$ Alternatively, vacuum vessels may be designed in accordance with the applicable sections of the Code as it applies to vacuum vessels or through other calculations approved by the authority having jurisdiction.

\section{Category III Vacuum Systems}

All design requirements contained in the Code apply for Category III vacuum systems. Vessels must be stamped with an ASME Section VIII manufacturer's stamp unless the vessel is authorized by the authority having jurisdiction. The provisions of this guideline specified for Category III systems define the equivalency requirements for Category III vessels without this stamp.

\section{B. Design Review}

The engineering evaluation prepared for Category III vacuum systems must be reviewed and approved by a qualified independent design professional (see Section III, Definitions), the Pressure Safety Committee, or a similarly qualified ad-hoc committee.

\section{Fabrication}

Category I and II vacuum systems should be fabricated in accordance with sound engineering practices defined by the responsible design engineer. Vacuum systems classified as Category III must be fabricated, inspected, and tested in accordance with written procedures and a formal quality assurance program satisfying DOE $O 414.1 \mathrm{C}$ requirements. ${ }^{5}$

\section{Welding}

Because of the risk of internal over-pressurization, personnel performing welding and brazing activities on Category III vacuum systems shall meet the qualification requirements identified in the American Welding Society (AWS) B2.1, as a minimum.

a. For all welding to pressure retaining components and attachments to pressure retaining components, all welding and brazing procedure specifications (WPS/BPS) and welder and brazer performance qualifications must meet the requirements of ASME Code, Section IX and/or AWS B2.1.

b. All welding and brazing of Category III systems must also meet the applicable design and fabrication code(s) that are employed in the design of the system.

c. Welding or brazing of specially designed seals, structural or electrical joints where pressure containment is provided by components that are not integral to the welding or brazing process may be qualified by the welding/brazing of sample joints on like materials with precise joint configurations and cross sectional areas that duplicate the designed component. These sample welds must be visually inspected and a minimum of 4 cross sections cut and examined by appropriate polishing and etching methods that reveal adequate fusion and penetration, and must contain no injurious defects. Welding or brazing of the final components must be done to a welding/brazing procedure specification that has duplicated essential and non-essential variables identified in ASME Section IX, paragraphs

\footnotetext{
${ }^{4}$ Code Case 2286 is fully incorporated into the 2007 ASME Code Section VIII, Division 2. It should be noted that 10 CFR 851 refers only to the 2004 version of the Code, which DOE has yet to resolve. Code Case 2286 still exists, but will be annulled soon since it has been incorporated into the Code.

${ }^{5}$ DOE O 414.1C Quality Assurance, http://www.directives.doe.gov/cgi-bin/explhcgi?gry1863498282;doe-130
} 
QW-250 or QB-250 as applicable for process(es) tested. These procedures must contain acceptability standards for the weld/braze joints. Similarly the performance qualifications of welders/brazers for these joints are qualified by producing and passing the actual sectioning test joints within the limitation of the essential and non-essential variables identified in the WPS/BPS. Maintenance of qualification and retests for failures must follow the requirements of ASME Section IX, paragraphs QW-320 and QW-322.

Records demonstrating conformance with these qualifications must be submitted and approved by the responsible vacuum system design engineer. Records of these qualifications must be maintained with the records for the vacuum system.

\section{Inspection}

All Category III vessels must be visually inspected during fabrication, testing, and operation by a qualified person to determine that the vessel has been constructed in accordance with design requirements and good engineering practice.

- Material condition and material property certifications shall be inspected upon receipt of materials used for construction of the vessel

- All welds and vessel materials shall be visually inspected

- Prior to and following all tests

- Prior to initial operation

- Periodically for operating vessels and systems subject to corrosion or degradation

These requirements apply except when internal components cannot be inspected without unwarranted effort. The authority having jurisdiction makes this determination.

Because of the additional risk of internal over-pressurization, personnel performing nondestructive examinations of Category III vacuum vessels and systems must meet qualification requirements defined by the American Society for Non Destructive Testing (ASNT) Specification SNT-TC-1A. . Personnel performing visual examinations must be qualified to SNTTC-1A or to a similar standard acceptable to the PSC.

Records demonstrating conformance with these qualifications must be submitted and approved by the responsible vacuum system design engineer. Records of these qualifications must be maintained with the records for the system.

\section{Testing}

All vacuum vessels should be tested by pumping out the vacuum volume and be shown to meet the vacuum design specification. Following the test the responsible engineer should examine the vessel and determine that no effect in excess of limits established by the engineer was experienced.

For ordinary vacuum vessels the test pressure should be full atmospheric pressure differential. For vacuum vessels not intended to be pumped out to the full atmospheric pressure differential, the test pressure should be $110 \%$ of the maximum allowable external differential pressure, but not more than full atmospheric pressure.

For a vacuum vessel within a pressure vessel, the test differential pressure should be $110 \%$ of the maximum allowed working pressure differential. Thin windows and other delicate equipment may be removed while testing the vacuum vessel. 
All vacuum tests should be documented with a brief description of the test and documentation should include two signatures: the responsible person and one witness. Records of these tests must be maintained.

\section{Pressure Relief Devices}

Pressure relief devices used in Category II or III vacuum systems must bear the ASME "UV" certification mark. Calculations must be performed and documented to demonstrate adequate sizing for venting capability of the pressure relief device(s).

In special applications where ASME-certified relief devices are not be available for Category II systems, operability tests demonstrating function and flow capacity of the relief device must be performed and documented. A vacuum system using a non-certified pressure relief device that has not been tested ${ }^{6}$ must be treated as a Category III system.

Spring-actuated pressure relief devices should be inspected and tested prior to installation and thereafter in accordance with the schedule required by National Board of Boiler and Pressure Vessel Inspectors (NBIC). Burst disks should be visually inspected as required by the NBIC. On-going inspections and tests for these devices are typically conducted at regular intervals not to exceed 5 years. Engineered or administrative controls are required to assure that the pressure relief devices are not altered or removed during the operating lifetime of the vessel. Safety wires/labeling are examples of this type of control. The particular pressure relief requirements should be noted in the engineering evaluation.

\section{E. Existing Vacuum Systems}

It is not the intent of this guideline to apply these requirements retroactively to existing vacuum systems. The department responsible for the current operation of a vacuum system constructed prior to Feb. $9,2007^{7}$ should ensure that it can be operated in a safe manner and that the vacuum system was designed and operated in a manner consistent with applicable engineering practices.

Questionable vessels or those with unknown histories should be re-tested as defined in this guideline. Operability of relief devices on pre-existing systems should be confirmed if such evidence does not exist (It is assumed that such evidence exists for National Board-certified pressure relief devices.) Bench-top tests of similar relief devices are acceptable if the relief device cannot be tested as installed. A written record of the decisions, judgments, tests, administrative controls, and hazard analysis that were necessary to approve these types of vessels should be maintained in the system records file.

\section{F. Records}

Pertinent design drawings, sketches, calculations, reviews, tests, inspections, material certifications, qualification records, and operating history required by this guideline should be documented and retained throughout the operation of the system. As required by Federal regulations, records of safety reviews associated with the system must be retained throughout the operations and for 5 additional years following shut-down of the system. For purposes of this

\footnotetext{
${ }^{6}$ As noted in Section $\mathrm{E}$, bench tests approved by the authority having jurisdiction are an adequate determination of acceptable pressure relief.

${ }^{7}$ Systems designed after February 9, 2007 are required to be compliant with the requirements of 10 CFR 851 or the equivalency requirements described in this guideline.
} 
requirement, inactive systems in storage are treated the same as an active system until it is officially "disposed." 


\section{Appendix A:}

\section{Engineering Evaluation Requirements}

Engineering evaluations should be prepared for all vacuum systems subject to this guideline. The responsible vacuum system design engineer prepares the evaluation, which should include the following:

- Design drawings, sketches, and calculations, including a stress/collapse analysis of all exceptional parts of the vessel

- A fabrication procedure, including a list of planned and completed inspections and any other quality control procedures taken.

- Acceptance tests planned or completed

- Description of and capacity requirements for pressure relief systems and associated tests

- A description of personnel hazards associated with vessel operation and the methods used for protection. The hazard analysis should address vessel application, operating limits and controls, possible effects in the event of vessel failure and inherent safeguards provided.

- The basis for the vacuum system classification (Category I, II, or III) 


\section{Appendix B:}

\section{Independent Review Requirements for Category III Vacuum Vessels}

All Category III vacuum vessels designed to this guideline must be reviewed by an independent design professional, the Pressure Safety Committee, or other similarly qualified ad hoc committee. The basis for the independent review is the engineering evaluation in Appendix A. The independent review should address as a minimum the following topics, as applicable:

\section{Design Specifications and Description}

- Physical layout

- Piping and instrumentation drawings

- Design parameters including:

- Maximum design/allowable working pressures

- Pressure vessel, piping and component ratings

- Stress calculations

- Maximum release rate and pressure relief capabilities

- Materials used and their suitability for application

- Quench protection description, if appropriate

\section{Reviews and Hazard Evaluations}

- Test plans and results, if any

- Department safety review(s) results

- Evaluation of oxygen deficiency hazard

- Stress analyses for custom-made equipment

- Failure scenarios that can over-pressure the vacuum volume

\section{Procedures}

- Fabrication procedure and inspections

- Operating and emergency procedures 